\title{
SCANNING KELVIN PROBE STUDY OF HYDROGEN FORMED DURING ATMOSPHERIC CORROSION
}

\author{
1'Darya RUDOMILOVA, ${ }^{1}$ Tomáš PROŠEK, ${ }^{2}$ Gabriela SCHIMO-AICHHORN, ${ }^{2}$ Ines TRAXLER, \\ ${ }^{3}$ Andreas MUHR, ${ }^{3}$ Hubert DUCHACZEK, ${ }^{3}$ Gerald LUCKENEDER \\ ${ }^{1}$ University of Chemistry and Technology Prague, Czech Republic, EU \\ darya.rudomilova@vscht.cz, tomas.prosek@vscht.cz \\ ${ }^{2}$ CEST Competence Center for Electrochemical Surface Technology, Linz, Austria, EU \\ gabriela.schimo@cest.at, ines.traxler@cest.at \\ ${ }^{3}$ Voestalpine Stahl GmbH, Linz, Austria, EU \\ Andreas.Muhr@voestalpine.com, Hubert.Duchaczek@voestalpine.com,
}

Gerald.Luckeneder@voestalpine.com

https://doi.org/10.37904/metal.2019.713

\begin{abstract}
One of the intensively studied issues regarding hydrogen embrittlement of advanced high strength steels (AHSS) is the absorption and diffusion of hydrogen produced by atmospheric corrosion. Scanning Kelvin Probe (SKP) is a tool sensitive enough to detect low amounts of hydrogen formed during atmospheric corrosion. In this work, SKP was used to study the effect of the presence of corrosion products on hydrogen uptake and permeation through AHSSs specimens. Corrosion was initiated on one side of the specimen contaminated with a corrosion activator, while Volta potential mapping on the opposite side allowed for in-situ hydrogen detection. Hydrogen release indicated by low potential areas in the maps corresponded to the locations of corrosion products on the opposite side. This shows that hydrogen entry is linked to the presence of red rust.
\end{abstract}

Keywords: High strength steels, hydrogen, atmospheric corrosion, SKP

\section{INTRODUCTION}

A topic of great importance in the frame of advanced high strength steels (AHSS) research is their susceptibility to hydrogen embrittlement (HE), as it can be an aspect limiting wider utilization of AHSS in different fields of industry. Detailed study of hydrogen entry caused by atmospheric corrosion is necessary in order to predict the threat of hydrogen-induced degradation during service of any steel structure. It was shown that even very low levels of absorbed hydrogen can lead to the change in the fracture behaviour [1-3]. Any techniques for studying the HE phenomena under atmospheric conditions should be sensitive enough and allow for in-situ hydrogen detection during exposure to a corrosive environment. The principle of the hydrogen detection is often based on the reaction of hydrogen permeating through a sample with species on the detection side. In case of the electrochemical permeation technique, hydrogen is introduced on one side of a steel membrane and after passing the metal is oxidized on the exit side by applying anodic polarization [4]. Evaluation of changes in measured anodic current allows for determination of hydrogen diffusion and trapping characteristics $[5,6]$. A modified EPT setup was used to study the influence of environmental parameters on hydrogen uptake behaviour, when instead of cathodic polarization on the entry side, corrosion reaction under conditions of cyclic corrosion test or outdoor exposures took place [7-10]. It was demonstrated that hydrogen entry can be influenced not only by the actual climatic parameters of the corrosion process, but also by formation of a layer of iron corrosion products (red rust) and its acidification. It should be taken into account that atmospheric corrosion is spatially very inhomogeneous as well as corrosion products distribution on the metal surface and hydrogen entry can differ from region to region. Techniques allowing for measurements of more localized hydrogen diffusion paths are needed for detailed studies. 
The scanning Kelvin probe (SKP) technique fulfils these requirements. It is sensitive to very low hydrogen concentrations and can be used for in-situ studies of localized hydrogen uptake. It maps contact potential difference (CPD) between the reference probe and the sample [11]. Hydrogen detection is based on the decrease of the steel work function when hydrogen permeating through the specimen reduces $\mathrm{Fe}^{3+}$ to $\mathrm{Fe}^{2+}$ of the native steel oxide layer [12]. Diffusible hydrogen can be quantitatively measured when steel is coated with $\mathrm{Pd}$, as it works like Pd:H electrode even in dry atmosphere [13]. SKP measurement of hydrogen on iron and steel with passive oxide film was shown to provide useful information about hydrogen permeation $[14,15]$. In the case of SKP, an area large enough to measure both affected and unaffected area can be scanned. Scanning Kelvin probe force microscopy (SKPFM), however, is able to measure only a small area, usually not exceeding $100 \times 100 \mu \mathrm{m}$. Thus, it is almost impossible to observe a CPD difference between the region with absorbed hydrogen and the reference surface. However, due to its high spatial resolution, SKPFM was applied to study hydrogen permeation within individual grains and microstructural features [16-20]. Rohwerder and Turcu [21] stated that SKPFM is subject to more artefacts than standard SKP and only the CPD contrast can be meaningful. In our previous study, it was underlined that changes of SKPFM tip potential due to tapping at the surface should be also taken into account as it can influence measured CPD, especially when concentration of hydrogen is very low [22]. For in-situ studies, detection of hydrogen entered into steel during corrosion with SKP seems thus preferable.

In this work, experiments with SKP were carried out in order to measure the hydrogen release at the exit side of steel specimens, while hydrogen was introduced into the specimens due to atmospheric corrosion on the opposite side. The effect of the presence of corrosion products on the entry side on the hydrogen uptake was evaluated.

\section{EXPERIMENTAL}

Complex phase steel CP1000 with ultimate tensile strength $\mathrm{Rm} 980 \mathrm{MPa}$ was used for the measurements. The chemical composition of the steel is given in Table 1. Sheet specimens of $0.8 \mathrm{~mm}$ thickness were mechanically polished. Pre-corroded entry surfaces were prepared by exposing specimens to two 24-hour cycles according to EN ISO 3231. Each cycle consisted of 8-hour exposure to air at $100 \%$ relative humidity $(\mathrm{RH})$ with addition of $0.2 \mathrm{I} \mathrm{SO}_{2}$ to $300-\mathrm{I}$ climatic chamber maintained at $40{ }^{\circ} \mathrm{C}$ and 16-hour exposure to air at $23 \pm 5{ }^{\circ} \mathrm{C}$ and $50 \pm 20 \% \mathrm{RH}$. The hydrogen detection (exit) side was isolated with tape during the pre-exposure to prevent corrosion. After formation of a red rust layer, specimens were annealed at $200{ }^{\circ} \mathrm{C}$ for 2 hours in order to remove any absorbed hydrogen.

Both the pre-corroded and reference freshly polished specimens were exposed to air at $55 \% \mathrm{RH}$ for 24 hours in order to produce stable and reproducible oxide layer on the exit side surface.

Table 1 Chemical composition of CP1000 AHSS; maximal contents of alloying elements given in wt.\%

\begin{tabular}{|c|c|c|c|c|c|c|c|c|c|c|}
\hline Material & $\mathbf{C}$ & $\mathbf{S i}$ & $\mathbf{M n}$ & $\mathbf{P}$ & $\mathbf{S}$ & $\mathbf{A l}$ & $\mathbf{C r}+\mathbf{M o}$ & $\mathbf{N b}+\mathbf{T i}$ & $\mathbf{V}$ & $\mathbf{B}$ \\
\hline CP1000 & 0.23 & 1 & 2.7 & 0.08 & 0.015 & 1.4 & 1 & 0.15 & 0.2 & 0.005 \\
\hline
\end{tabular}

After measuring the initial CPD, the entry side of the specimens was contaminated with $\mathrm{NaCl}$ solution to obtain the surface chloride concentration of $10 \mu \mathrm{g} / \mathrm{cm}^{2}$, approximately. The CPD mapping of the opposite (exit) specimen side was performed using SKP from Wicinski \& Wicinski GbR with Ni probe of $170 \mu \mathrm{m}$ diameter. The experiments were carried out in the atmosphere of controlled $\mathrm{RH}$ of $85-90 \%$ ensuring corrosion reaction on the hydrogen absorption side. Potential of the SKP tip was calibrated using Cu crucible filled with saturated $\mathrm{CuSO}_{4}$ solution and CPD was recorded against standard hydrogen electrode. Repeated scans were carried out in order to investigate evolution of CPD in time. 


\section{RESULTS AND DISCUSSION}

SKP scans were performed on the side opposite to the side contaminated with $\mathrm{NaCl}$ and exposed to humid air. In Figure 1, the evolution of CPD maps during the corrosion process is shown. The area corresponding to the contaminated zone is indicated by dotted lines. CPD distribution maps of a specimen without red rust layer on the back (Figures 1a-c) illustrate that the CPD distribution was quite homogeneous shortly after the contamination. It started to decrease at the left hand side of the contaminated area a few hours later. In case of the pre-corroded specimen (Figures 1d-f), a CPD drop was observed already in the first measurement only 2 hours after the contamination. It is known that hydrogen diffusion coefficient in CP1000 is quite high [23] and the time lag for the first specimen can thus be attributed to the time needed for red rust formation. In contrary, the pre-corroded specimen was already covered with corrosion products and the hydrogen entry process could start immediately after the contamination. The expansion of the low CPD area can be related to the lateral diffusion of hydrogen in the steel, which was reported elsewhere [15].
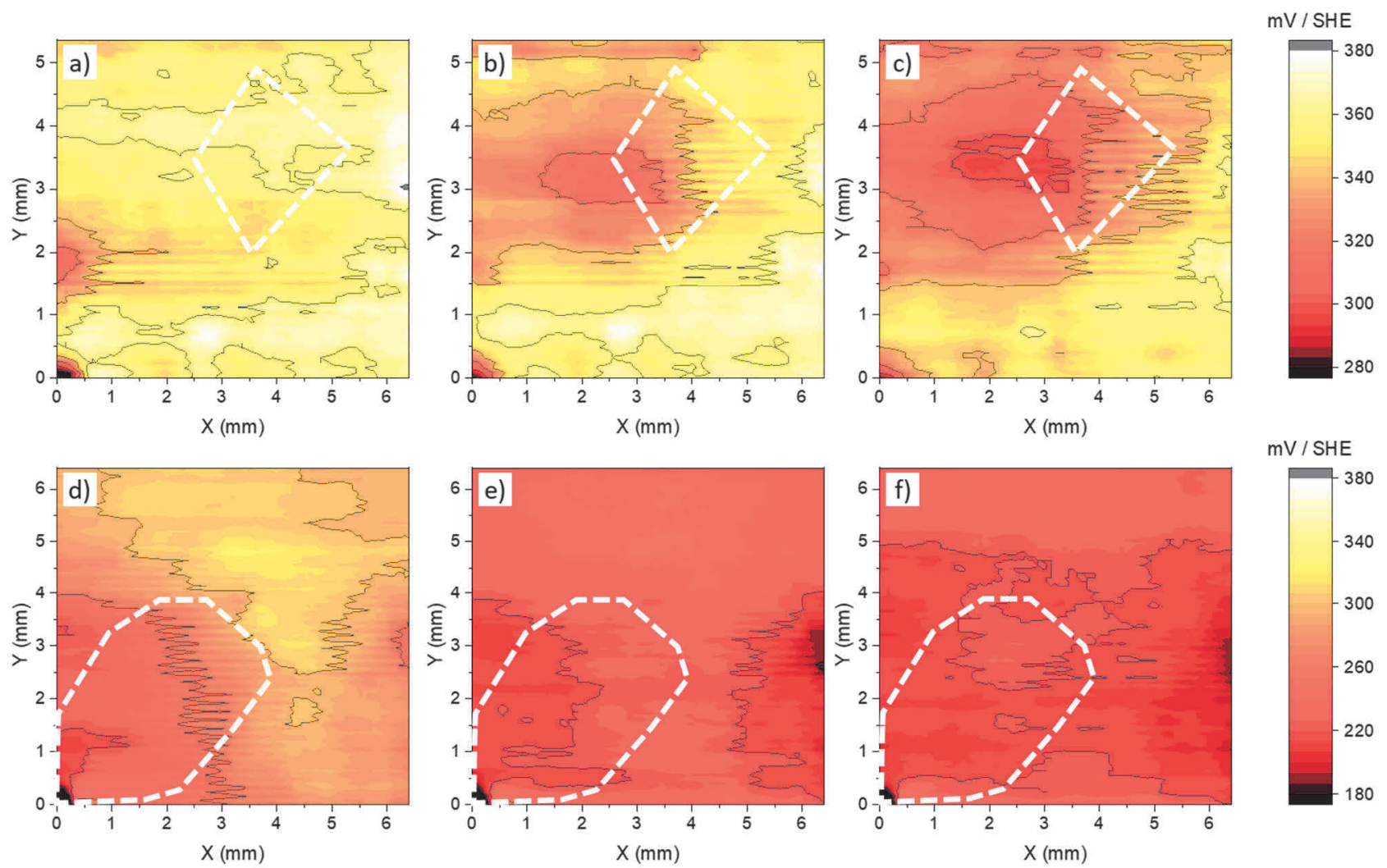

Figure 1 CPD maps measured during atmospheric corrosion of the opposite side for a specimen without red rust layer after a) 2 hours, b) 21 hours and c) 42 hours after contamination with corrosion activator and for a pre-corroded specimen after d) 2 hours, e) 6 hours and f) 29 hours after contamination

Figure 2a indicates that the area of lower CPD corresponds to the region of red rust formation and there is no significant CPD decrease in the contaminated area without corrosion products. For the pre-corroded specimen in the Figure $\mathbf{2 b}$, the low CPD area correlates with the contaminated area.

The evolution of CPD in time is presented in plots in Figure 3. Plotted data are the average values of CPD for two selected lines inside the contaminated area and in the reference area. CPD before the contamination was slightly lower than CPD of the reference area during the first measurement indicating possible oxidation of the detection side. The problem with the stability of the potential on the detecting side can be solved in the future 
by using Pd coating [24]. For the fresh specimen, a decrease of CPD occurred 7 hours after the contamination and the total CPD drop of the contaminated area versus reference area was $50 \mathrm{mV}$. In contrast, the total CPD drop measured on the pre-corroded specimen was $120 \mathrm{mV}$. The significant decrease of CPD at the contaminated area appeared rapidly and it was detected already during the first measurement. Only a slight further decrease was observed. It is also obvious that CPD of the reference area decreased as well but with a lower rate and achieved near the same value of CPD at the end of the exposure. It can be assigned not only to the lateral diffusion, but also to possible other hydrogen entry sites due to the presence of the red rust layer.
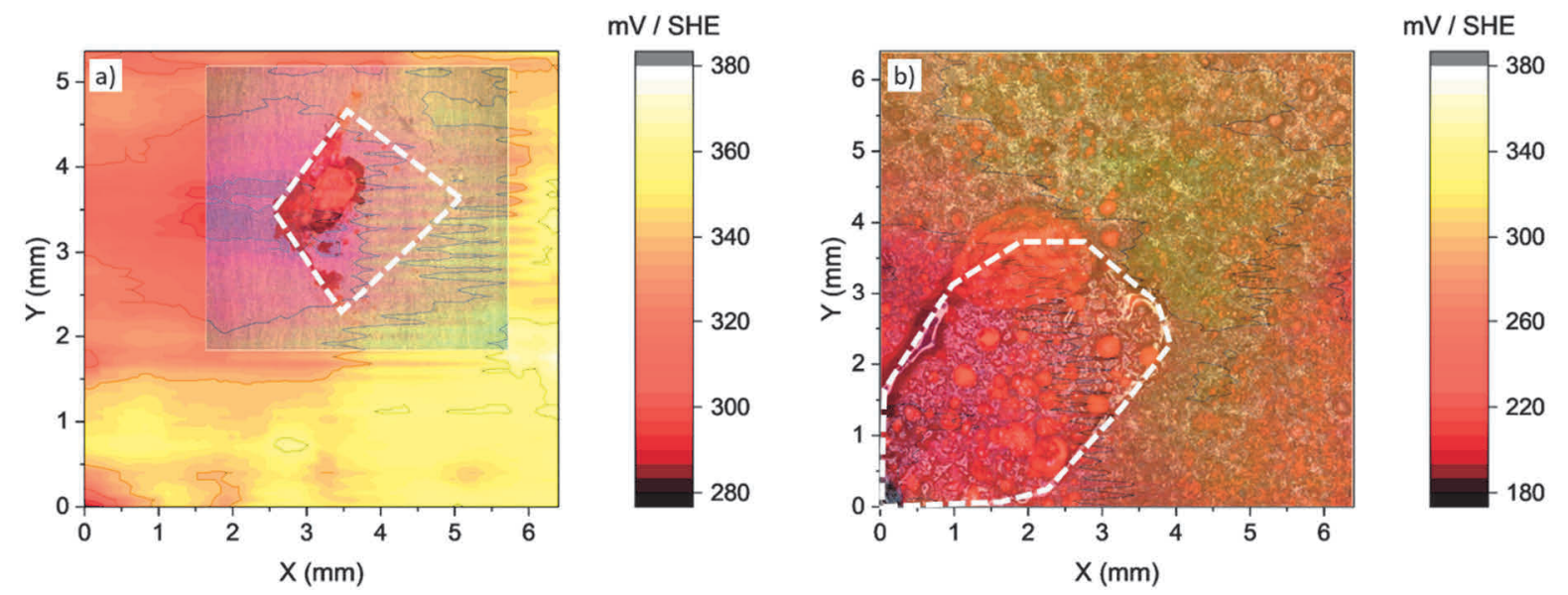

Figure 2 Overlaid CPD maps and micrographs of the opposite side of specimens a) with fresh surface and b) pre-corroded surface after 42 hours and $2 \mathrm{~h}$ of exposure to humid air
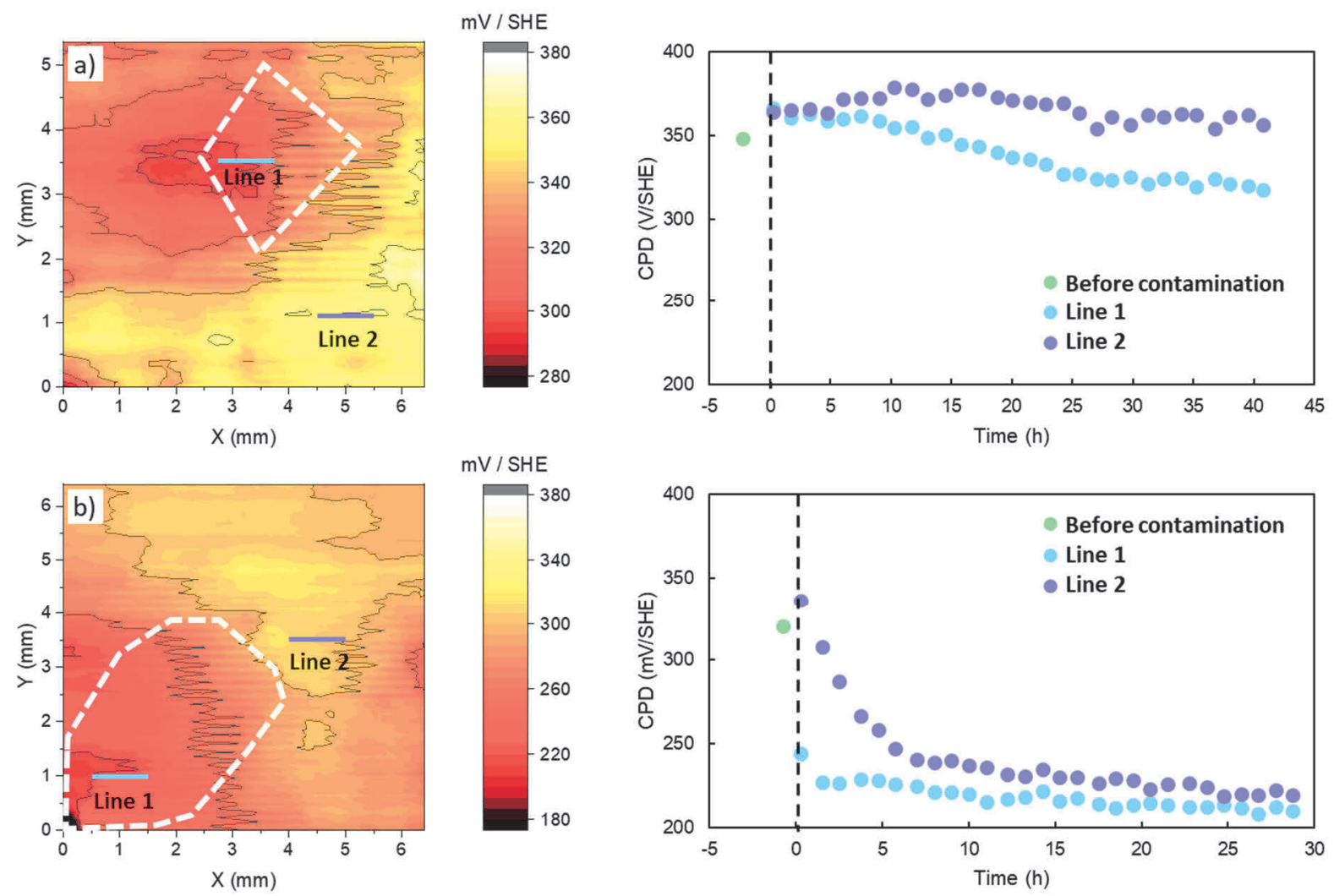

Figure 3 Evolution of average CPD for selected lines measured on the opposite side of the specimen a) with fresh surface and b) with pre-corroded surface 
These observations confirm the major role of the presence of corrosion products on hydrogen entry. It is in accordance with previous works suggesting that red rust formed on steel causes a drop in $\mathrm{pH}$, which enables enhanced hydrogen uptake into steel $[7,25]$. It should also be noted that red rust present on the pre-corroded specimen contains sulphates which were reported to further contribute to the $\mathrm{pH}$ drop and able to enhance hydrogen uptake [26].

\section{CONCLUSIONS}

SKP was used for in-situ hydrogen detection during atmospheric corrosion. CPD measurements carried out on a pre-corroded specimen and on a specimen without red rust indicate that the process of hydrogen uptake is linked to the presence of corrosion products. Presence and possibly the chemical nature of iron corrosion products (red rust) can significantly enhance hydrogen entry.

\section{ACKNOWLEDGEMENTS}

\section{A part of this research was financially supported by the Czech Science Foundation, project No. 17-22586S.}

\section{REFERENCES}

[1] LI, S., ZHANG, Z., AKIYAMA, E., TSUZAKI, K. and ZHANG, B. Evaluation of susceptibility of high strength steels to delayed fracture by using cyclic corrosion test and slow strain rate test. Corrosion Science. 2010. vol. 52, no. 5, pp. 1660-1667.

[2] AKIYAMA, E., MATSUKADO, K., LI, S. and TSUZAKI, K. Constant-load delayed fracture test of atmospherically corroded high strength steels. Applied surface science. 2011. vol. 257, no. 19, pp. 8275-8281.

[3] AKIYAMA, E., WANG, M., LI, S., ZHANG, Z., KIMURA, Y., UNO, N. and TSUZAKI, K. Studies of evaluation of hydrogen embrittlement property of high-strength steels with consideration of the effect of atmospheric corrosion. Metallurgical and Materials Transactions A. 2013. vol. 44, no. 3, pp. 1290-1300.

[4] DEVANATHAN, M.A.V. and STACHURSKI, Z. The adsorption and diffusion of electrolytic hydrogen in palladium. Proceedings of the Royal Society of London. Series A. Mathematical and Physical Sciences. 1962. vol. 270 , no. 1340 , pp. 90-102.

[5] LIU, Q., VENEZUELA, J., ZHANG, M., ZHOU, Q. and ATRENS, A. Hydrogen trapping in some advanced high strength steels. Corrosion Science. 2016. vol. 111, pp. 770-785.

[6] ZAKROCZYMSKI, T. Adaptation of the electrochemical permeation technique for studying entry, transport and trapping of hydrogen in metals. Electrochimica Acta. 2006. vol. 51, no. 11, pp. 2261-2266.

[7] AKIYAMA, E., LI, S., SHINOHARA, T., ZHANG, Z. and TSUZAKI, K. Hydrogen entry into Fe and high strength steels under simulated atmospheric corrosion. Electrochimica Acta. 2011. vol. 56, no. 4, pp. 1799-1805.

[8] AKIYAMA, E., LI, S., KATAYAMA, H., ZHANG, Z., ZHAO, K. and OSHIKAWA, W. Electrochemical Hydrogen Permeation Test under Controlled Temperature and Humidity after Outdoor Exposure at Beijing, Chongqing and Okinawa. ISIJ International 2016. vol. 56, no. 3, pp. 436-443.

[9] LI, S., AKIYAMA, E., SHINOHARA, T., MATSUOKA, K. and OSHIKAWA, W. Hydrogen entry behavior into iron and steel under atmospheric corrosion. ISIJ international. 2013. vol. 53, no. 6, pp. 1062-1069.

[10] OOTSUKA, S., FUJITA, S., TADA, E., NISHIKATA, A. and TSURU, T. Evaluation of hydrogen absorption into steel in automobile moving environments. Corrosion Science. 2015. vol. 98, pp. 430-437.

[11] STRATMANN, M. and STRECKEL, H. On the atmospheric corrosion of metals which are covered with thin electrolyte layers-I. Verification of the experimental technique. Corrosion Science. 1990. vol. 30, no. 6-7, pp. 681696.

[12] KRASEMANN, M., STRECKEL, H., HOFFMANN, K. and GRABKE, H.J. Detection of hydrogen ingress into iron oxide and iron oxy-hydroxide layers by the Kelvin probe. In: Proceedings of the Electrochemical Society. 1998. p. 207. 
[13] EVERS, S. and ROHWERDER, M. The hydrogen electrode in the "dry": a Kelvin probe approach to measuring hydrogen in metals. Electrochemistry Communications. 2012. vol. 24, pp. 85-88.

[14] NAZAROV, A.P., MARSHAKOV, A.I. and RYBKINA, A.A. Iron hydrogenation under atmospheric corrosion. Studies using a scanning vibrating microscope. Protection of Metals and Physical Chemistry of Surfaces. 2015. vol. 51, no. 3, pp. 347-359.

[15] NAZAROV, A., VUCKO, F. and THIERRY, D. Scanning Kelvin Probe for detection of the hydrogen induced by atmospheric corrosion of ultra-high strength steel. Electrochimica Acta. 2016. vol. 216, pp. 130-139.

[16] KOYAMA, M., BASHIR, A., ROHWERDER, M., MERZLIKIN, S.V., AKIYAMA, E., TSUZAKI, K. and RAABE, D. Spatially and kinetically resolved mapping of hydrogen in a twinning-induced plasticity steel by use of scanning Kelvin probe force microscopy. Journal of The Electrochemical Society. 2015. vol. 162, no. 12, pp. C638-C647.

[17] HUA, Z., WANG, D., LIU, Z., ZHANG, Y. and ZHU, S. Hydrogen distribution at twin boundary in austenitic stainless steel studied by scanning Kelvin probe force microscopy. Materials Letters. 2019. vol. 234, pp. 175-178.

[18] KRIEGER, W., MERZLIKIN, S.V., BASHIR, A., SZCZEPANIAK, A., SPRINGER, H. and ROHWERDER, M. Spatially resolved localization and characterization of trapped hydrogen in zero to three dimensional defects inside ferritic steel. Acta Materialia. 2018. vol. 144, pp. 235-244.

[19] NAGASHIMA, T., KOYAMA, M., BASHIR, A., ROHWERDER, M., TASAN, C.C., AKIYAMA E., RAABE, D. and TSUZAKI, K. Interfacial hydrogen localization in austenite/martensite dual-phase steel visualized through optimized silver decoration and scanning Kelvin probe force microscopy. Materials and corrosion. 2017. vol. 68, no. 3, pp. 306-310.

[20] SENÖZ, C., EVERS, S., STRATMANN, M. and ROHWERDER, M. Scanning Kelvin probe as a highly sensitive tool for detecting hydrogen permeation with high local resolution. Electrochemistry Communications. 2011. vol. 13, no. 12, pp. 1542-1545.

[21] ROHWERDER, M. and TURCU, F. High-resolution Kelvin probe microscopy in corrosion science: scanning Kelvin probe force microscopy (SKPFM) versus classical scanning Kelvin probe (SKP). Electrochimica Acta, 2007. vol. 53, no. 2, pp. 290-299.

[22] RUDOMILOVA, D., PROŠEK, T., SCHIMO-AICHHORN, G., MUHR, A., DUCHACZEK, H. and LUCKENEDER, G. Hydrogen detection in high strength steels by means of SKPFM. In METAL 2018: 27rd International Conference on Metallurgy and Materials. Ostrava: TANGER, 2018, pp. 572-577.

[23] RUdOMILOVA, D., PETREK, T. PROŠEK, T., ŠEFL, V., DUCHACZEK, H., ZWETTLER, F., MUHR, A. and LUCKENEDER, G. Comparative study of devices for hydrogen permeation measurements. Materials and Corrosion. 2018. vol. 69, no. 10, pp. 1398-1402.

[24] EVERS, S., SENÖZ, C. and ROHWERDER, M. Hydrogen detection in metals: a review and introduction of a Kelvin probe approach. Science and technology of advanced materials. 2013. vol. 14, no. 1, p. 014201.

[25] AKIYAMA, E., MATSUKADO, K., WANG, M. and TSUZAKI, K. Evaluation of hydrogen entry into high strength steel under atmospheric corrosion. Corrosion Science. 2010. vol. 52, no. 9, pp. 2758-2765.

[26] TSURU, T., HUANG, Y., ALI, M.R. and NISHIKATA, A. Hydrogen entry into steel during atmospheric corrosion process. Corrosion science. 2005. vol. 47, no. 10, pp. 2431-2440. 